\title{
Water purification and biomineralization using nanofibres-based membrane technology
}

\author{
Manish Kumar, Siddhant Kumar, Samar Agnihotri, Bharat Singh Rajpurohit \\ and Jaspreet Kaur Randhawa*
}

Indian Institute of Technology Mandi, Mandi 175 005, India

\begin{abstract}
Population of world and industrialization are increasing rapidly due to which the amount of fresh water is decreasing. There is a need to promote a novel costeffective technique to purify the contaminated water. Nanotechnology provides extraordinary nanomaterials with unique properties which can be used to purify the water. In this article the use of polymeric hybrid membranes is discussed. A novel high flux filtration hybrid membrane system, consisting of a three-layer composite with hierarchical structures, i.e. highly porous hydrophilic material coated top layer, an electrospun nanofibrous barrier layer in the middle; for support the bottom layer is made of nonwoven fibrous web to provide high tensile strength up to $40 \mathrm{MPa}$, more durability and high retention ratio.
\end{abstract}

Keywords: Hybrid membrane, electrospinning technique, nanomaterials, porous nanofibres.

\section{Introduction}

ACCORDING to the WHO report ${ }^{1}$, there are about 2.2 billion people (one in three people of the world) in the world who do not have access to safe drinking water and 4.2 billion people who have lack of appropriate sanitation services. The contribution of the developing countries is more.

The world is facing challenges to meet the rising demands of consumable water as the available supply of freshwater is limited as the population is increasing rapidly and distribution of water is limited for use (Figure 1). In the past two decades, excessive increase in industrialization has further made this situation worse. Developing countries are more affected by the shortage of drinkable water because of a lack of infrastructure and an increase in population. In countries like India, whose $70 \%$ of the population live in villages, the above situation is noticeable. Lack of developed infrastructure and the poor economy are the prime reasons for this. The village areas do not have safe drinking water, electrical power, communication, sanitation and hence these issues are important. In Indian villages, water is drawn from the near

\footnotetext{
*For correspondence. (e-mail: jaspreet@iitmandi.ac.in)
}

by river or lake for daily use such as drinking, cooking and cleaning. Heavy metals, dyes and drug pollutions present in water bodies severely affect the human body upon consumption. Also, the toxic nature of heavy metals and drugs causes damage to human and animal body organs. Limits of heavy metals, metalloids and transition metals in drinking water and their toxic symptoms are shown in Table 1. It is necessary to provide safe drinking water at low cost with high reliability in these areas. There is a need for the development of innovative new techniques and materials to address challenges related to safe potable water. Though new techniques are continually being examined, these need to be cost effective, highly durable and more effective than current options for the removal of contaminants from water.

Nanotechnology is progressively being distinguished as a region of science and innovation that could assume a job in tending to a portion of short-comings of conventional purpose of-use (POU) devices. The comparison of POU water filtration techniques is shown in Table 2. Nanotechnology encompasses the creation and utilization of materials, devices and systems at the level of atoms and molecules, cutting across disciplines such as chemistry, physics, biology, engineering, and materials science. Nanomaterials and nanostructures have nanoscale dimensions that range from 1 to $100 \mathrm{~nm}$, and often exhibit novel and significantly changed physical, chemical and biological properties. These have a result of their structure, larger surface area per unit volume and quantum effects that occur at the nanoscale. Proponents propose that nanotechnology-based materials could prompt less expensive, more durable, and more effective water treatment advances that address the issues of developing countries. A few water treatment techniques and devices that incorporate nanoscale materials are as of now economically accessible, and others are being developed. These nanotechnology-based items incorporate water filters, filtration hybrid membranes, catalysts, and nanoparticles for groundwater remediation.

More efficient water treatment techniques are required because prevention of water pollution is not possible. Legislation also supports the use of more efficient water treatment techniques, which can lead to better purification results of waste water and the recovery of valuable compounds (minerals) from wastewaters. One filtration 

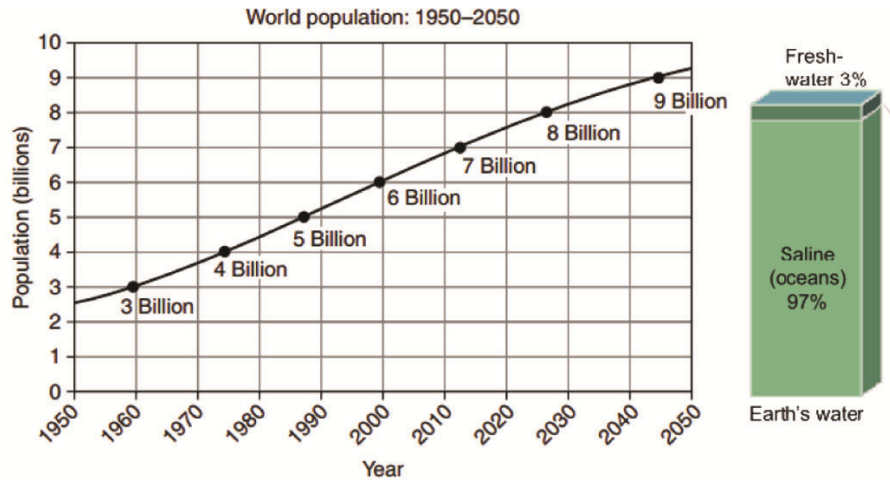

Distribution of Earth's Water

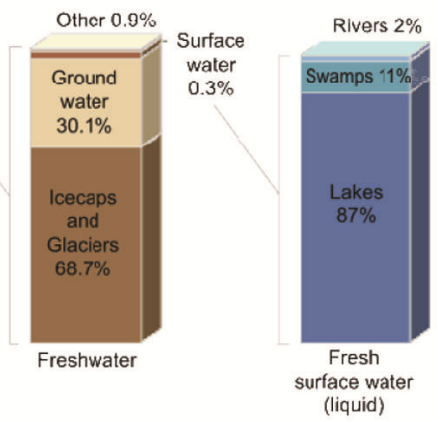

Figure 1. Growing population and distribution of usable water on earth. Source: US Census Bureau, International Data Base, December 2010 Update $^{2-4}$.

Table 1. Limits of heavy metals, metalloids and transition metals in drinking water and their toxic symptoms

\begin{tabular}{|c|c|c|c|}
\hline $\begin{array}{l}\text { Heavy metal/metalloid/ } \\
\text { transition metal }\end{array}$ & $\begin{array}{l}\text { Drinking water } \\
\text { quality guideline }\end{array}$ & Toxic symptoms & Reference \\
\hline Cyanide & $0.05 \mathrm{mg} / 1$ & $\begin{array}{l}\text { Weakness and confusion, headache, nausea/feeling 'sick to your } \\
\text { stomach', gasping for air and difficulty breathing, seizures cardiac } \\
\text { arrest. Loss of consciousness/'passing out' }\end{array}$ & 5 \\
\hline Molybdenum (as Mo) & $0.07 \mathrm{mg} / 1$ & $\begin{array}{l}\text { Severe headaches, night blindness, nausea, vomiting, central scotomas, } \\
\text { generalized oedema, lethargy, disorientation and coma }\end{array}$ & \\
\hline Lead (as $\mathrm{Pb})$ & $0.01 \mathrm{mg} / 1$ & $\begin{array}{l}\text { Abdominal pain, abdominal cramps, aggressive behaviour, } \\
\text { constipation, sleep problems, headaches, irritability }\end{array}$ & \\
\hline Mercury (as $\mathrm{Hg}$ ) & $0.001 \mathrm{mg} / \mathrm{l}$ & $\begin{array}{l}\text { Mood swings, nervousness, irritability, and other emotional changes, } \\
\text { insomnia, headache, abnormal sensations, muscle twitching, } \\
\text { tremors, weakness, muscle atrophy, and decreased cognitive } \\
\text { functions. }\end{array}$ & \\
\hline Arsenic (metalloid) & $10 \mu \mathrm{g} / 1$ & $\begin{array}{l}\text { Long-term symptoms: hyperpigmentation, hypopigmentation, skin, } \\
\text { bladder, lung cancers, dermal lesions. }\end{array}$ & 6,7 \\
\hline Cadmium & $3 \mu \mathrm{g} / 1$ & $\begin{array}{l}\text { Carcinogenic prostate cancer, lung cancer. Accumulates in kidneys } \\
\text { and causes dysfunction. }\end{array}$ & \\
\hline Chromium & $\begin{array}{l}50 \mu \mathrm{g} / 1 \text { (for total } \\
\text { chromium) }\end{array}$ & $\begin{array}{l}\text { Carcinogenic. } \mathrm{Cr}^{+3} \text { belongs to Group } 3 \text { and } \mathrm{Cr}^{6+} \text { belongs to Group } 1 \text {. } \\
\text { Carcinogenic, causes, e.g. stomach cancer and lung. }\end{array}$ & \\
\hline Copper & $\begin{array}{l}2 \mathrm{mg} / \mathrm{l} \text { over } 1 \mathrm{mg} / 1 \\
\text { cause staining }\end{array}$ & $\begin{array}{l}\text { Essential nutrient. high dosage can cause gastric irritation, nausea, } \\
\text { liver and kidney damage and anaemia. }\end{array}$ & \\
\hline Nickel & $70 \mu \mathrm{g} / 1$ & $\begin{array}{l}\text { Lack of evidence of carcinogenic risk from oral exposure. Can cause } \\
\text { allergy when in skin contact. Carcinogenic when inhaled }\end{array}$ & \\
\hline Zinc & $\begin{array}{l}\text { No health-based } \\
\text { guideline }\end{array}$ & $\begin{array}{l}\text { Essential nutrient. No effect on health at levels found in drinking } \\
\text { water. More than } 4 \mathrm{mg} / \mathrm{dm}^{3} \text { deteriorates water taste }\end{array}$ & \\
\hline $\begin{array}{l}\text { Manganese } \\
\quad \text { (transition metal) }\end{array}$ & $0.05 \mathrm{mg} / 1$ & $\begin{array}{l}\text { Essential nutrient. Over } 0.1 \mathrm{mg} / \mathrm{dm}^{3} \text { deteriorates water taste and } \\
\text { therefore lower concentrations are favoured }\end{array}$ & 8 \\
\hline
\end{tabular}

technique, which has been of interest, is membrane filtration technology. Membrane technology can isolate heavy metals, salts and nutrients effectively from water, also at low concentrations, which is not always possible with traditional water treatment techniques. The main drawback of membrane technologies is membrane fouling, which reduces the membrane permeate flux and separation efficiency. Membrane techniques were combined into hybrid processes to increase the efficiency of water treatment to reduce fouling and to widen the application areas of membrane technologies.

This article highlights the uses of nanotechnology in areas relevant to water purification techniques, including separation and functionalization membrane for water filtration, as well as nanomaterials and nanoparticles for use in water biomineralization. The toxic potential of heavy metal ions for human body and the environment is also discussed.

\section{Membrane technology for water purification}

Membrane technology has become a distinguished separation technology. The main strength of membrane technology is the fact that it works without the addition of chemicals, with a relatively low energy use and well-arranged process. Membrane technology is a generic term for a unique, characteristic separation processes. 


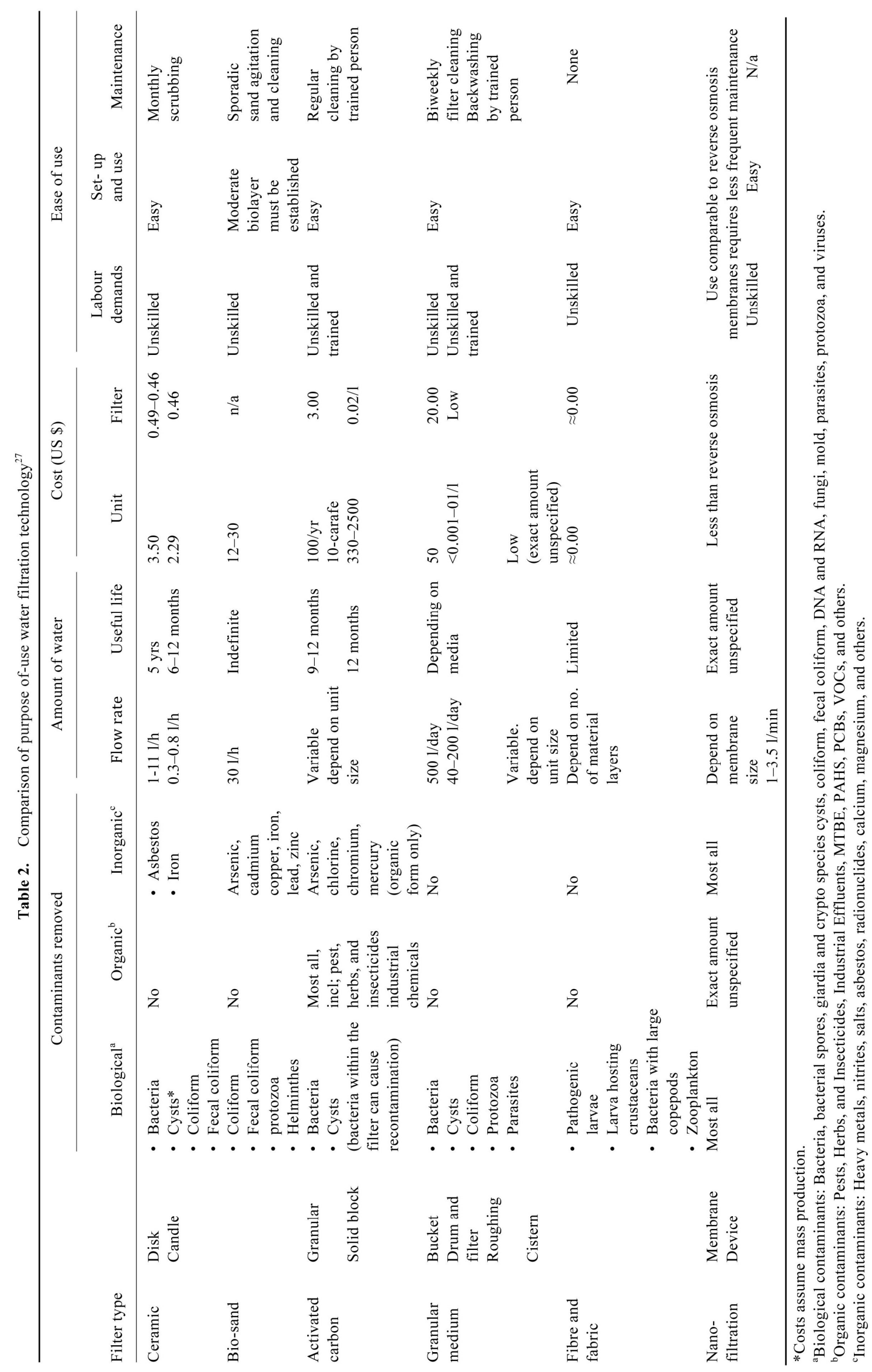


Membranes are utilized regularly to make fresh drinkable water from surface, ground, and wastewater. Membrane technology is now competitive for conventional techniques. The membrane filtration technique is mostly based on the presence of semi permeable membranes. Membrane techniques are mostly based on a pressure difference between membrane feed and permeate sides. Certain substances can go through the membrane, while other substances are caught at the membrane. Membrane filtration can be used as an advanced technique for sediment purification, flocculation, adsorption (sand filters, active carbon filters, and ion exchangers), extraction and distillation.

The commercial applications are limited to distillation, ion-exchange and chemical treatment, due to their relatively high energy cost and intrinsic problems. Membrane separation technique is more energy-efficient as compared to distillation, ion-exchange, safe and secure (compared to chemical treatment), which can overcome several disadvantages of conventional techniques. Numerous new filtration advancements have been made and their effect on the water refinement industry has turned out to be more noticeable ${ }^{9}$.

These membrane filtration techniques can be classified into four categories based on their pores size and pressure applied: microfiltration (MF), ultrafiltration (UF), nanofiltration (NF) and reverse osmosis (RO).

All filtration membranes have been fabricated from inorganic material such as ceramic, organic materials (polymer) or hybrid materials (combination of ceramic and polymer materials $)^{10}$. There are no criteria to choose materials and technique to fabricate the membrane, except for the concern of cost effectiveness, which is the main issue of water purification.

\section{Challenges in membrane filtration technology}

The advancement in membrane technology has accelerated the productivity of purified water as compared to the conventional techniques. However, with the rapid population increase and growing ecological concerns, the need to discover new water filtration techniques with significant energy and financial benefits has become a pressing worldwide issue. Membrane technology as of now faces some challenges, the principal challenge is to distinguish or to make new materials (e.g. high durability, low cost and fewer environmental concerns) that can fabricate more cost-effective membranes for water treatment. The second challenge is to design and to upgrade the structure and morphology in existing membranes that can lead to considerable increment in filtration efficiency. (e.g. high retention, high permeation flux, and low pressure drop). To satisfy all these conditions only a limited selection of materials such as ceramic ${ }^{11}$, synthetic polymers (e.g., polyacrylonitrile (PAN), polysulfone (PSU), polyethersulfone (PES), polyvinylidene fluoride (PVDF), cellulose acetate (CA) and cross-linked polyamide
$(\mathrm{PA}))^{12}$, have been successfully used for commercial membranes for water treatment. Ceramic membranes are mechanically durable and chemically inert, but the high cost has seriously affected their usage, particularly in developing countries. Polymers, such as PAN, PSU, PES and PVDF, are routinely used for the fabrication techniques of MF and UF membranes, which have good chemical resistance, mechanical properties and processability, and are cost-effective.

\section{Fabrication of nanofibrous membrane}

There are different techniques available to fabricate the membrane such as polymer solution casing, phase inversion, sputtering thin film deposition.

\section{Polymer solution casting}

In this technique, the polymer is dissolved or dispersed to produce solvent, and then coated onto a substrate, and then the solvent is removed by air dry or heating the solid layer on the substrate. The casted layer can be stripped from the substrate to produce a self-sustainable film. Before or after stripping, the cast film can be overlapped with other films or with other materials to develop multilayer membrane.

\section{Phase inversion}

This is a controlled process of polymer transformation from liquid phase to solid phase. Basically, there are four techniques to make a phase inversion membrane: (a) precipitation from vapour phase, (b) precipitation by controlled evaporation, (c) thermally induced phase separation, (d) immersion precipitation.

\section{Sputter deposition}

This is a physical vapour deposition (PVD) technique of thin film deposition on the substrate by sputtering. It involves ejecting material from a source which will deposit onto the substrate (reactive gases can also be used to sputter compounds).

\section{Electrospinning}

This is one of the most adaptable fabrication and manufacturing methods for making nanofibres-based membranes. Figure 2 shows the schematic diagram of a standard electrospinning system. The polymer solution to be electrospun is filled in a syringe, whose flow rate is controlled by a syringe pump-flow controller. An electric field is applied between the needle of the syringe and the collector with the aid of a high-voltage DC power supply. 
With increasing electric field, at the optimized distance between the needle and the collector, the hemispherical surface of the liquid at the tip of the needle changes to conical shape, which is known as the Taylor cone. When the electric forces overcome the surface tension, a jet of the polymer solution is produced, which is then collected in the collector that is grounded.

\section{Thin film composite membranes}

The thin film composite (TFC) film has turned into the best in class for water filtration, including endeavours to enhance its execution by fusing added substances. Filling nanoparticles (NPs), such as silica, clay, zeolite, and metalorganic frameworks inside the membrane results in the thin film nanocomposites (TFNs) membranes with enhanced performance of the membrane. Also, following the preparation by post treatments is another way to improve the membrane-based products. As for the plan and streamlining of structure and morphology to improve the filtration process for existing membranes. Chu et al. ${ }^{13}$ have demonstrated that TFC membranes are a practical model for the fabrication of polymer membranes. Typically, TFC membranes consist of a two- or three-layer structure as shown in Figure 3. The bottom layer is made of a nonwoven fibre web substrate (e.g. PET or polyethylene/polypropylene nonwoven fibre web). The bottom layer provides the overall mechanical strength to the filtration membrane. The typical thickness of the bottom nonwoven web is in the range of a few hundred microns, having fibres with diameters of about $10-30$ microns.

Ma et al. ${ }^{15}$ have reported that the TFNC system has a relatively high porosity (about $40-60 \%$ ), the ultimate tensile strength up to $40 \mathrm{MPa}$ the Young's modulus up to $500 \mathrm{MPa}$, and the elongation-to-break ratio around $20 \%$ (which provides sufficient elastic property to the filtration membrane).

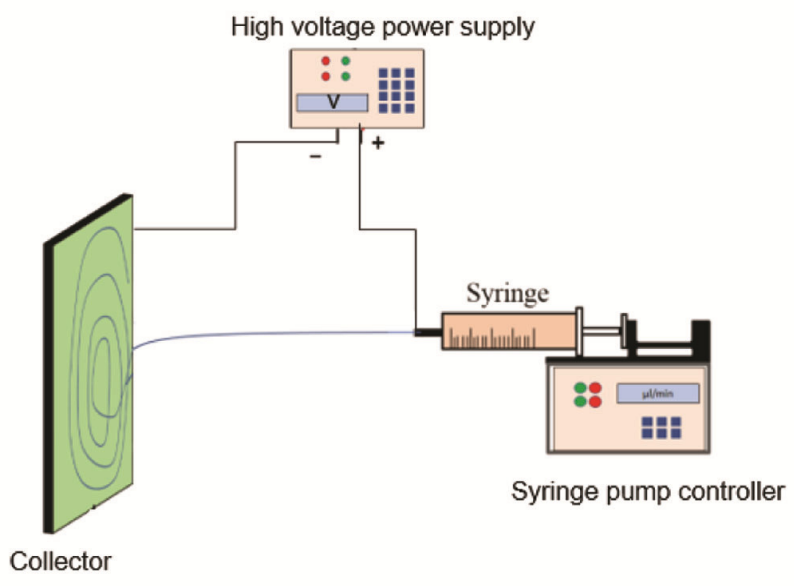

Figure 2. Schematic of electrospinning set-up used for the fabrication of nanofibrous membrane.
Based on the new concept of Thin Film Nano fibre composite (TFNC) membranes, several improvements in filtration performance were made as a result of (1) the extraordinary properties of nanofibres (e.g. interconnected three-dimensional porous structure and very large surface-to-volume ratio) in the middle-layer support or the barrier layer and (2) the implementation of directed water channels created through the interface between the nanofibres web and the polymer matrix in the barrier layer or filtration membrane.

Since we do not know the nature (hydrophobic versus hydrophilic) of the ideal interface to transport water molecules, some literature has clearly indicated the potential advantages of directed water channels in the barrier layer - for example, using the barrier layer of polyvinyl alcohol $^{16}$, cellulose ${ }^{17}$, and chitosan ${ }^{18}$, on top of electrospun PAN scaffolds. Currently, the use of some very small nanofibres (with diameters in the range of a few nanometers), such as uniform cellulose nanofibres ${ }^{19}$, and oxidized carbon nanotubes ${ }^{16}$, has further confirmed the possibility of creating a thinner and more effective barrier layer with high water permeability.

Most of the commercial supporting membranes are fabricated by hydrophobic materials, for example, PVDF, PES and PAN, because these polymers are stable for long-term operation in aqueous solutions. PVA, cellulose, chitosan, chitin and polysaccharide nanofibres are used as barrier layers or filtration membranes and usually have a hydrophilic surface. The cellulose nanofibre based TFNC membrane has a water contact angle of $10.9^{\circ}$.

\section{Functionalization of the TFNC membranes}

The average pore size of TFNC membrane system made with nonwoven fibres is far greater than that of typical waterborne viruses (a few tens of nanometers) ${ }^{20}$ and bacteria ( 0.2 to a few microns). It is marked that the both bacteria and viruses can frame charged species at certain $\mathrm{pH}$ extremes in suspension (as related with their surface property or isoelectric point (pI)). To effectively remove bacteria and viruses from contaminated water, the microfibres membranes have to be modified with opposite charged monomers which will create a positive or negative charge on the fibre surface that will have the capacity to adsorb the opposite charged bacteria and viruses. As demonstrated in Figure 4, the barrier layer or nanofibre filtration membrane is deposited on the PET nonwoven fibre web. The top layer is coated with either a hydrophilic or hydrophobic substance depending on the impurities present in water. The major interactions between membrane surface and target impurities include electrostatic interactions, specific coordination complex formation and hydrophobic interactions. (Ex. PAN Electrospun nanofibrous membranes are modified with positively charged monomers for the removal of negatively charged 

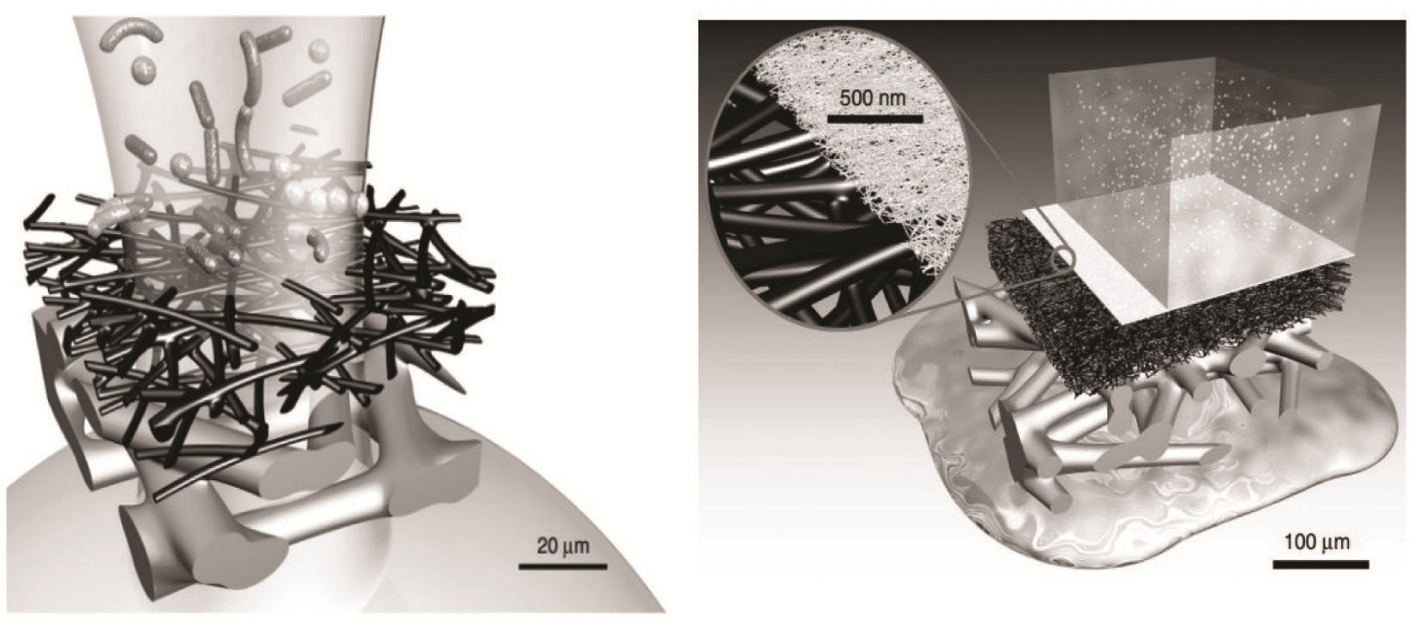

Figure 3. Hierarchical structure of TFNC membranes ${ }^{14}$.

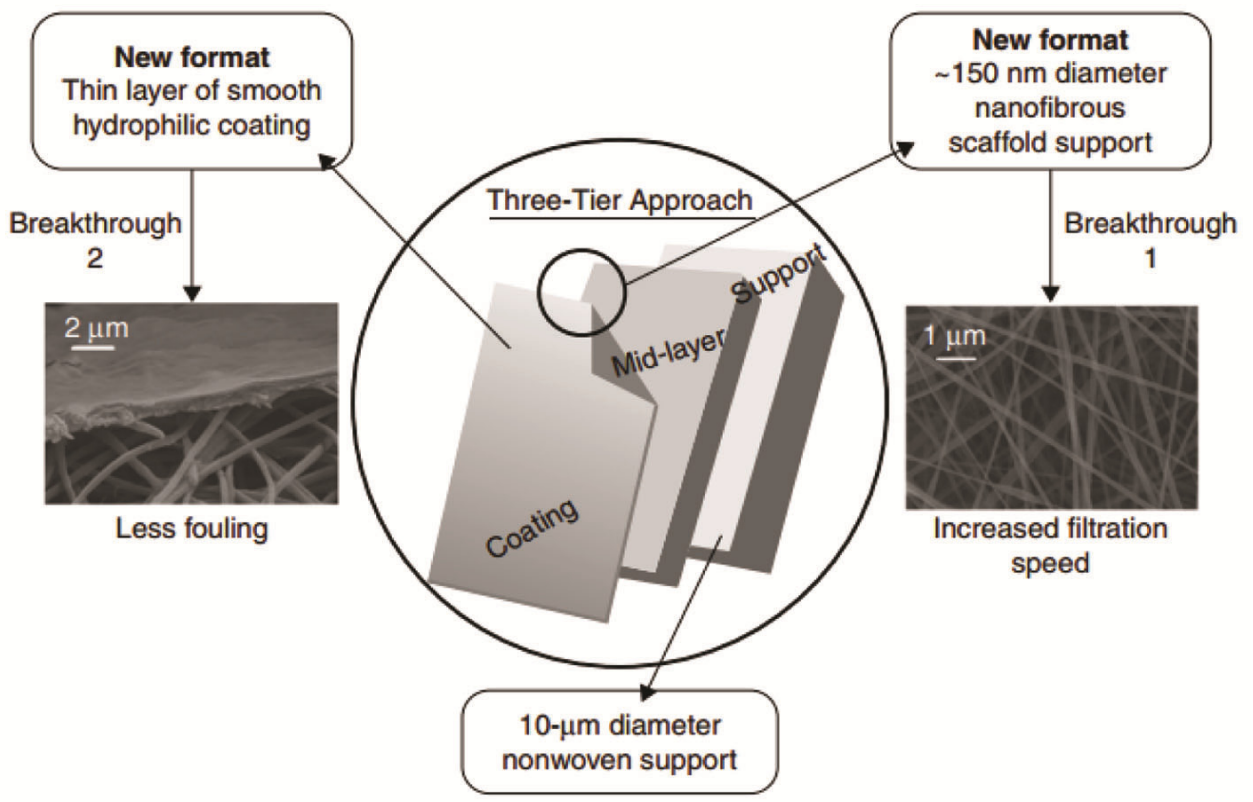

Figure 4. Schematic representation of TFNC membrane ${ }^{13}$.

impurities by simply dip-coating the electrospun PAN nanofibres in a positively charged monomer.)

Chu and Hsiao ${ }^{13}$ fabricated a PVA electrospun nanofibrous membrane with $100 \pm 10 \mathrm{~nm}$ mean diameter of the fibres from an aqueous solution. They have tested with $0.2 \mu \mathrm{m}$ sized particle impurities (250 ppm), after cross-connection with glutaraldehyde (GA) in acetone medium. The retention ratio was reported higher than 95\%. The nanofibrous membrane showed high Young's modulus and high tensile strength because of the formation of cross-linked networks; the membrane will be safe under typical cross flow conditions and it can sustain at a high pressure ${ }^{11}$.

Yoon et al. ${ }^{18}$ developed a PES nanofibrous membrane from a mixed solvent of DMF and $N$-methyl-pyrrolidone
(NMP) at different concentration ratios of the solvents. At a fixed PES polymer concentration of $26 \mathrm{wt} \%$, the fibre diameter was varied from 550 to $760 \mathrm{~nm}$ with varying NMP solvent concentration (from 0 to $50 \mathrm{wt} \%$ ). To oxidize PES electrospun nanofibres ammonium persulphate (APS) is used. After oxidation the water contact angle of the nanofibrous membrane will change from $127^{\circ}$ to $28^{\circ}$. For water purification the modified membrane is more suitable. After modification of the electrospun PES nanofibre membrane, water could approach a value of $2.91 \times 10^{3} \mathrm{~L} / \mathrm{m}^{2} \mathrm{~h} / \mathrm{psi}$, with high Young's modulus of $280 \mathrm{MPa}$. Tang et al..$^{21}$ fabricated PES electrospun nanofibrous membranes from lower polymer concentrations (i.e. 20-22 wt \%) using a solvent mixture of DMF: NMP in the ratio $60: 40$. This condition is more 
optimized compared to the one mentioned, because the adhesion of PES nanofibres with the supporting layer PET is good and it shows uniformity of nanofibres.

Gopal et $a l^{22}$ and Barhate et $a l^{23}$ fabricated selfsustainable nanofibrous microfilter membranes (without supporting layer, PET nonwoven) of PVDF, PAN and PSU polymers. The fibre diameter of these nanofibres ranged from 200 to $1000 \mathrm{~nm}$ and mean pore size of the nanofibres ranged from 1.5 to $5.0 \mu \mathrm{m}$. They have reported that the porosity of these membranes is almost $95 \%$. They also obtained an impressive value for water permeability due to highly porous structure of these membranes. They reported particle retention ratios of more than $90 \%$ for $1.0 \mu \mathrm{m}$ particle size at a concentration of $100 \mathrm{ppm}$. The smaller particles of the impurities, which are in the diameter range of $0.1-0.5 \mu \mathrm{m}$, could pass through the membrane with only a low retention ratio $(14-47 \%)$ of the membrane, this is the limitation for the application of the membrane for removal of small bacteria such as $B$. diminuta.

Chu and $\mathrm{Hsiao}^{13}$ coated CNTs onto PVDF/PTFE microporous substrates by the sonication/filtration process using CNTs/dimethylsulphoxide (DMSO) suspensions and studied that the antibacterial property for this filter is up to $3 \mathrm{LRV}$ (Log removal value) against MS2 (the original concentration of MS2 was $\sim 106 \mathrm{pfu} / \mathrm{mL}$ ). Heavy doping of CNT would dramatically decrease the permeation flux, although higher LRV of 5-7 could be achieved.

Juholin ${ }^{24}$ modified the nanofiltration membrane with $\mathrm{ZnO}$ coating for real mine wastewater purification. Commercial nanofiltration membranes are coated with $\mathrm{ZnO}$ using an atomic layer deposition (ALD) technique. The coated nanofiltration membranes are compared to uncoated commercial membranes. The membranes are applied to separate sulphate, nitrate, chloride and manganese from real mine wastewaters. Characteristics of the membranes, removal efficiencies are reported higher than $91 \%$.

The photocatalytic execution is assessed by concentrating the degradation of $\mathrm{RhB}$ dye as a model impurity ${ }^{25}$. In this procedure, $10 \mathrm{mg}$ of $\alpha-\mathrm{Fe}_{2} \mathrm{O}_{3}$ sample is suspended in $10 \mathrm{ml} \mathrm{RhB}$ aqueous solution. The solution is stirred on a magnetic stirrer and sonicated for $30 \mathrm{~min}$ in the dark environment to ensure an adsorption/desorption equilibrium, and the suspension is then exposed to a Xe light, which is placed at around $10 \mathrm{~cm}$ from the reactor. A $400 \mathrm{~nm}$ cut-off filter is used to absorb the UV light which is placed above the reactor. At given illumination time intervals, samples are collected frequently to observe the $\mathrm{RhB}$ degradation by UV-Vis spectroscopy. They have reported the effects of higher surface area; pore structures improved the photocatalytic effect for $\mathrm{RhB}$ degradation in presence of visible light.

Thanaa Shalaby et al..$^{26}$ reported the antibacterial activity of PAN nanofibres coated with $\mathrm{Ag}\left(0.5 \% \mathrm{AgNO}_{3}\right.$ and exposed to UV rays for 0,3 and $6 \mathrm{~h}$ ) and they coated
PAN nanofibre with different concentrations of $\mathrm{ZnO}$ Nano particles (1-3 wt \%) and different concentrations of $\mathrm{CuO}$ NPs $(1-3 \mathrm{wt} \%)$ to check for Gram-negative bacteria (E. coli) and Gram-positive bacteria (S. aureus) using agar disk diffusion assay.

\section{Current status of the Indian membrane-based market}

Due to the high demand for membrane-based techniques for desalination, water purification and wastewater treatment, the Indian membrane technology market is expected to witness more development than those in other areas of the world. Figure 5 shows the membrane market growth of $15 \%$ in 2012 in India compared to Europe. During 2014-19 the Indian membrane market was expected to grow at a rate of around $14 \%$ (ref. 26).

In India, RO membranes are one of the key development drivers. The demand in different Indian areas for RO membranes is increasing due to the high total dissolved solids (TDS), bacteria and water contamination. Therefore, in the future the RO membranes segment will keep on developing in India's membranes market.

\section{Biomineralization}

This is the procedure by which organisms form minerals. The mineral formation is governed by the numerous organisms which are recognized as abiotic mineralization. In contrast, utilization of new biotechnological devices could support the reuse of wastewater and improve the quality of seawater and freshwater. Such is the situation of biomineralization, a process that is interceded by microorganisms and other organisms for the formation of minerals from ions present in the surrounding environment. A specific type of biomineralization is microbiological carbonates precipitation (MICP), and is characterized as the procedure including the formation of minerals mediated by bacteria because of the cellular activity that promotes the physicochemical conditions required to carry out the formation and growth of the biominerals. There is a great variety of structures and, in nature, more than 60 different types of biological minerals have been identified in organisms.

\section{Types of biomineralization}

\section{Biological-induced mineralization}

In biologically-induced mineralization the chemical modification of an environment is mediated by the biological activity producing oversaturation and precipitation of biominerals. As shown in Figure $6 a$, the precipitation of minerals which occurs as a result of the interactions 


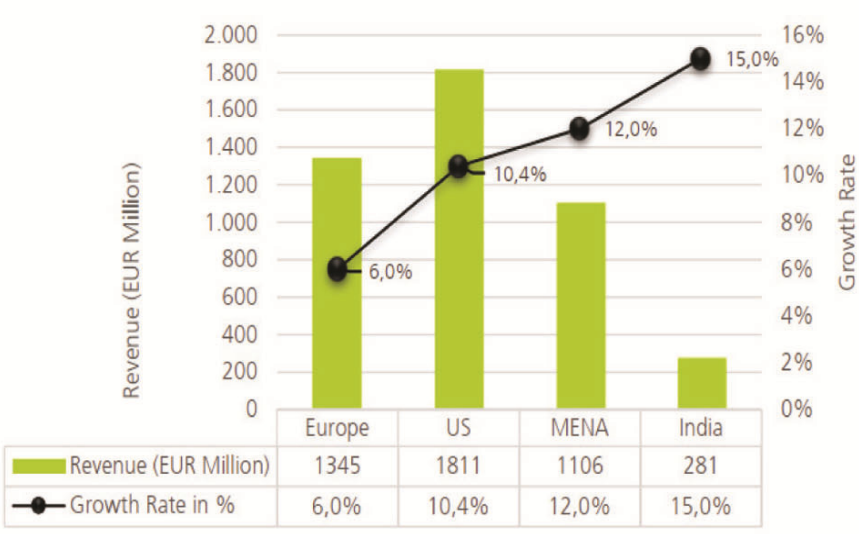

Top ten desalination markets by expected contracted capacity

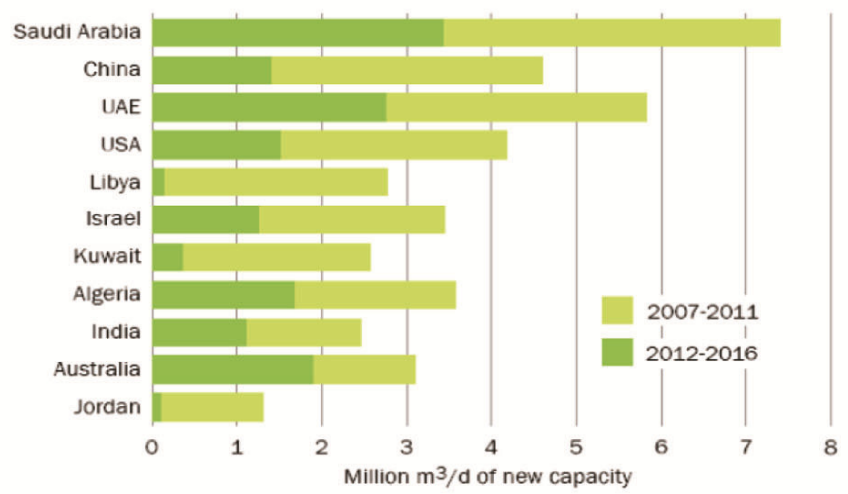

Figure 5. Membrane-based systems market in water and wastewater treatment industry (Source: GWI 2011 market revenue by region, global 2012).
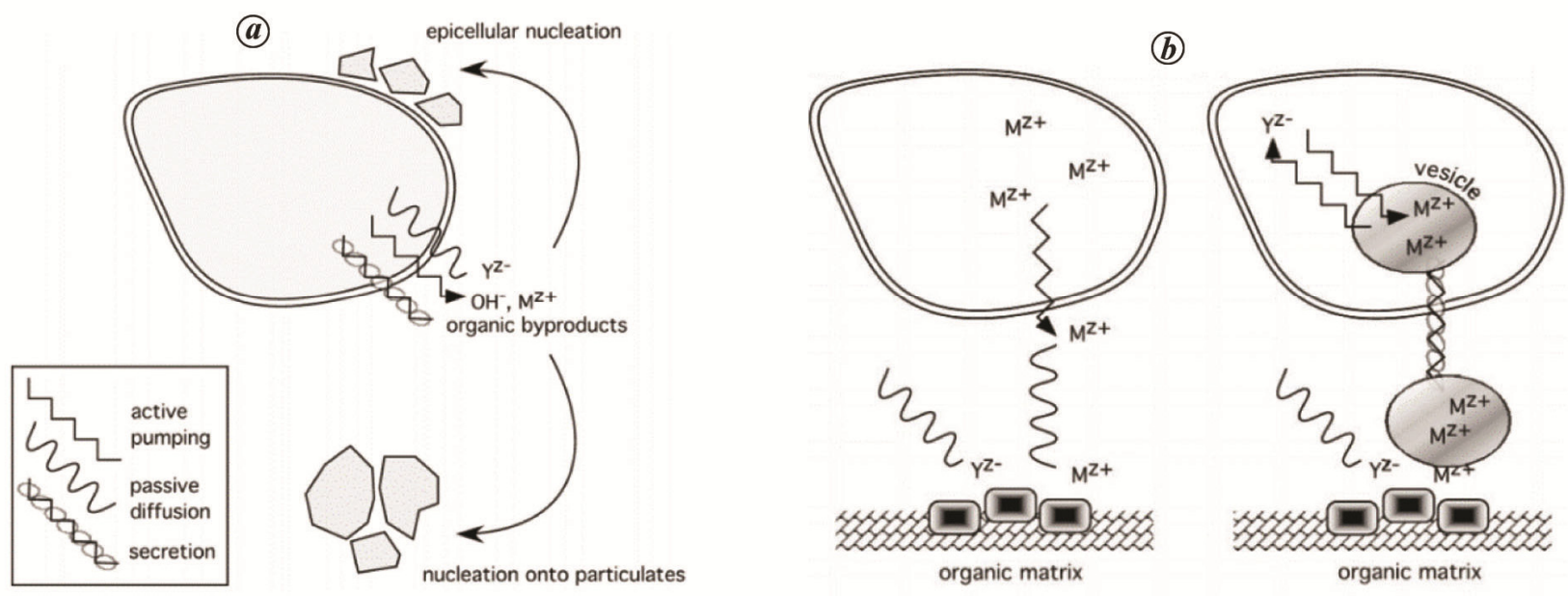

Figure 6. Schematic of (a) biologically induced and (b) biologically controlled mineralization (Weiner and Dove $\mathrm{e}^{28}$ ).

between biological activities and environmental activities is known as biological induced biomineralization.

\section{Biologically controlled mineralization}

In biologically controlled mineralization, the organism utilizes cell exercises to coordinate the nucleation, development, and morphology and target location of the mineral that is deposited. While the level of control varies across species, almost all controlled mineralization processes occur in an isolated situation. The outcome can be remarkably sophisticated, species-specific products that give the organism specialized biological functions. Biologically controlled mineralization processes can be divided in three types, viz. extracellular, intercellular or intracellular. These distinctions refer to the mineralization site with reference to the cells responsible for the mineralization process. But mineralization processes cannot be classified in this simple manner. In some situa- tions, mineral formation starts within the cell and then proceeds outside it.

\section{Conclusion}

In this article we have discussed the electrospun nanofibrous hybrid membrane system for water purification, which is a cost-effective and energy-saving system. The hybrid membrane is made by different polymers and modified with nanomaterials such as metal oxide nanoparticles to increase antibacterial properties and hydrophilic coating to change the contact angle of water with the nanofibrous membrane. These modified membranes offer 2-5 times higher purification than that of normal membranes, with high retention capability.

1. World Health Organization, 2019; http://www.who.int

2. Anon., Water treatment solution, Lenntech, 2011; http://www. lenntech.com (accessed on 18 September 2018). 
3. Gleick, P. H., Water sources. In Encyclopedia of Climate and Weather (ed. Schneider, S. H.), Oxford University Press, New York, 1996, vol. 2, pp. 817-823.

4. US Census Bureau, Population Division, International Data Base, December 2010 update; https://www.census.gov (accessed on 5 September 2018).

5. Indian Standard Drinking Water-Specification (Second Revision), Bureau of Indian Standards, IS 10500, 2012.

6. World Health Organization, Guidelines for drinking water quality, 2011; http://apps.who.int

7. IARC, Arsenic, metals, fibres and dusts. Vol. 100C. A review of human carcinogens. IARC monographs on the evaluation of carcinogenic risks to humans. International Agency for research on Cancer, World Health Organization, 2012.

8. World Health Organization, Manganese in Drinking-water Background document for development of WHO Guidelines for Drinking-water Quality. WHO/SDE/WSH/03.04/104/Rev/1, 2011; http://www.who.int

9. Van der Bruggen, B. and Vandecasteele, C., Distillation vs membrane filtration: overview of process evolutions in seawater desalination. Desalination, 2002, 143, 207-218.

10. Kumar, B. and Fellner, P., Polymer-ceramic composite protonic conductors. J. Power Sources, 2003, 123, 132-136.

11. Bein, T., Synthesis and applications of molecular sieve layers and membranes. Chem. Mater., 1996, 8, 1636-1653.

12. Ulbricht, M., Advanced functional polymer membranes. Polymer, 2006, 47, 2217-2262.

13. Chu, B. and Hsiao, B. S., The role of polymers in breakthrough technologies for water purification. J. Polym. Sci. Part B, 2009, 47, 2431-2435.

14. Ma, H., Burger, C., Hsiao, B. S. and Chu, B., Ultra-fine cellulose nanofibers: New nano-scale materials for water purification. J. Mater. Chem., 2011, 21, 7507-7510.

15. Ma, H. et al., High-flux thin-film nanofibrous composite ultrafiltration membranes containing cellulose barrier layer. J. Mater. Chem., 2010, 20, 4692-4704.

16. Wang, X., Chen, X., Yoon, K., Fang, D., Hsiao, B. S. and Chu, B., High flux filtration medium based on nanofibrous substrate with hydrophilic nanocomposite coating. Environ. Sci. Technol., 2005, 39, 7684-7691.

17. Ma, H. et al., Thin-film nano fibrous composite ultrafiltration membranes based on polyvinyl alcohol barrier layer containing directional water channels. Ind. Eng. Chem. Res., 2010, 49 11978-11984.

18. Yoon, K., Hsiao, B. S. and Chu, B., Formation of functional polyethersulfone electrospun membrane for water purification by mixed solvent and oxidation processes. Polymer, 2009, 50(13), 2893-2899.

19. Ma, H., Burger, C., Hsiao, B. S. and Chu, B., Ultra-fine polysaccharide nanofibrous membranes for water purification. Biomacromolecules, 2011, 12, 970-976.

20. Krug, R. M. and Wagner, R. R., Virus. In Encyclopedia Britannica, 2011; http://www.britannica.com/EBchecked/topic/630244/ virus (accessed on 10 September 2018).

21. Tang, Z. et al., Design and fabrication of electrospun polyethersulfone nanofibrous scaffold for high-flux nanofiltration membranes. J. Polym. Sci., Part B, 2009, 47, 2288-2300.

22. Gopal, R., Kaur, S., Ma, Z., Chan, C., Ramakrishna, S. and Matruura, T., Electrospun nanofibrous filtration membrane. J. Membr. Sci., 2006, 281, 581-586.

23. Barhate, R. S., Loong, C. K. and Ramakrishna, S., Preparation and characterization of nanofibrous filtering media. J. Membr. Sci., 2006, 283, 209-218.

24. Juholin, P., Hybrid membrane processes in industrial water treatment. Separation and recovery of inorganic compounds University of Oulu Graduate School; University of Oulu, Faculty of Technology Acta Univ. Oul. C 595, 2016.

25. Chao Wang and Zhixiong Huang, Controlled synthesis of $\alpha-\mathrm{Fe}_{2} \mathrm{O}_{3}$ nanostructures for efficient photocatalysis. Mater. Lett., 2016, 164, 194-197.

26. Thanaa Shalaby, Ola Mahmoud and Affaf Al-Oufy, Antibacterial silver embedded nanofibers for water disinfection. Int. J. Mater. Sci. Appl., 2015, 4(5), 293-298.

27. Overview and comparison of conventional treatment technologies; http://www.merid.org/nano/watertechpaper (accessed on 15 September 2018).

28. Weiner, S. and Dove, P. M., An overview of biomineralization processes and the problem of the vital effect. Rev. Mineral. Geochem., 2003, 54(1), 1-29.

ACKNOWLEDGEMENTS. We thank Nation Mission on Himalayan Studies for financial support.

doi: $10.18520 / \mathrm{cs} / \mathrm{v} 120 / \mathrm{i} 5 / 809-817$ 